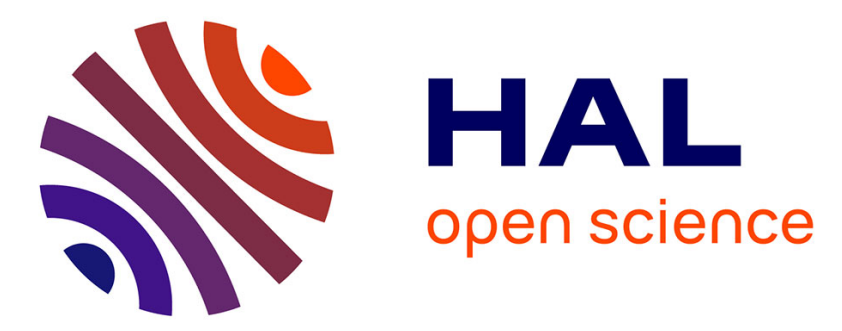

\title{
Dislocation dynamics in alkali halide single crystals investigated by nuclear spin relaxation measurements
}

\author{
W. Alsem, A. Sleeswyk, H. Hackelöer, R. Münter, H. Tamler, O. Kanert
}

\section{To cite this version:}

W. Alsem, A. Sleeswyk, H. Hackelöer, R. Münter, H. Tamler, et al.. Dislocation dynamics in alkali halide single crystals investigated by nuclear spin relaxation measurements. Journal de Physique Colloques, 1980, 41 (C6), pp.C6-146-C6-149. 10.1051/jphyscol:1980638 . jpa-00220076

\section{HAL Id: jpa-00220076 https://hal.science/jpa-00220076}

Submitted on 1 Jan 1980

HAL is a multi-disciplinary open access archive for the deposit and dissemination of scientific research documents, whether they are published or not. The documents may come from teaching and research institutions in France or abroad, or from public or private research centers.
L'archive ouverte pluridisciplinaire HAL, est destinée au dépôt et à la diffusion de documents scientifiques de niveau recherche, publiés ou non, émanant des établissements d'enseignement et de recherche français ou étrangers, des laboratoires publics ou privés. 


\title{
Dislocation dynamics in alkali halide single crystals investigated by nuclear spin relaxation measurements
}

\author{
W. H. M. Alsem $\left({ }^{*}\right)$, A. W. Sleeswyk $\left({ }^{*}\right)$, H. J. Hackelöer $\left({ }^{* *}\right)$, R. Münter $\left({ }^{* *}\right)$, H. Tamler $\left({ }^{* *}\right)$ \\ and $\mathrm{O}$. Kanert $(* *)$ \\ (*) Department of Applied Physics, Rijksuniversiteit Groningen, \\ Materials Science Centre, Nijenborgh 18,9747 AG Groningen, The Netherlands \\ (**) Institut für Physik, Universität Dortmund, Postfach 500500, 46 Dortmund 50, W. Germany
}

\begin{abstract}
Résumé. - La résonance magnétique nucléaire est appliquée à l'étude de la variation de la vitesse des dislocations avec la contrainte de compression appliquée dans des cristaux d'halogénures alcalins. $T_{1 \rho}$ a été mesurée en fonction du taux $\dot{\varepsilon}$ de la déformation plastique. La route moyenne des dislocations mobiles a été déterminée. Nous indiquons les résultats des expériences sur de différents noyaux, sur de différentes orientations des cristaux et sur des températures différentes.

Abstract. - Dislocations moving at various velocities in deforming alkali halide single crystals were studied using the technique of pulsed nuclear magnetic resonance. The spin lattice relaxation rate in the rotating frame is measured as a function of the plastic deformation rate $\dot{\varepsilon}$. From this the mean free path of mobile dislocations can be determined. The results for different resonant nuclei, different crystal orientations with respect to the crystal axis and different temperatures are presented.
\end{abstract}

1. Introduction. - For some years now the technique of pulsed nuclear magnetic resonance has been successfully applied in the study of dislocation dynamics $[1,2,3]$. In the experiments mainly the spinlattice relaxation time $T_{1}$ in the presence of a rotating resonant magnetic field $H_{1}$ has been measured as a function of the plastic deformation rate $\dot{\varepsilon}$, varied over a fairly wide range $\left(10^{-4} \mathrm{~s}^{-1} \leqslant \dot{\varepsilon} \leqslant 10^{2} \mathrm{~s}^{-1}\right)$. For a comprehensive theoretical survey of the dislocation induced relaxation reference should be made to Wolf and Kanert [4]. The physical model of dislocation motion used, assumes a thermally activated jerky motion of mobile dislocations between strong obstacles in the crystal, viz. forest dislocations and impurities. The possibility of detecting dislocations in cubic lattices using NMR is due to the disturbed lattice symmetry around dislocations that gives rise to an electric field gradient. Analyses of the experiments are based on the following expression of the relaxation rate derived in [4] which is related to the quadrupolar and dipolar field, $H_{\mathrm{Q}}$ and $H_{\mathrm{D}}$, respectively :

$$
R_{\mathrm{D}}^{\rho} \equiv 1 / T_{1 \rho}=\frac{A}{\gamma^{2}\left(H_{1}^{2}+H_{\mathrm{D}}^{2}+H_{\mathrm{Q}}^{2}\right)} \cdot \frac{1}{\varphi b L} \cdot \dot{\varepsilon}
$$

where $A$ represents a quadrupolar constant, b the Burgers vector, $L$ the mean free path and $\dot{\varepsilon}$ is according to Orowan given by :

$$
\dot{\varepsilon}=\varphi b \rho_{\mathrm{m}}\langle v\rangle,
$$

where $\varphi$ is the Schmid factor, $\rho_{\mathrm{m}}$ the mobile dislocation density and $\langle v\rangle$ represents the mean velocity of the mobile dislocations given by $L / \tau(\tau=$ inverse of the jump rate of the moving dislocations).

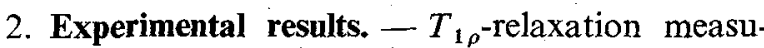
rements have been performed on different ultra pure alkali halide single crystals $\left(\mathrm{Ca}^{++}\right.$. concentration $\lesssim 5 \mathrm{ppm})$ as a function of $\dot{\varepsilon}$ with compression along an $\langle 100\rangle$ direction. In addition, $T_{1 \rho}$ experiments were carried out on $\mathrm{NaCl}$ single crystals varying the crystal orientation with respect to the compression axis and varying the temperature. The crystals were compressed using a hydraulic system. A special frame is mounted on the exciter head (Zonic Xcite 1105) to be able to deform the crystals which are placed within an NMR coil between the poles of an 1.4 T electromagnet with iron core. A Bruker pulse spectrometer type SXP 4-100 that was triggered by the hydraulic system has been used for the NMR measurements. To get the dynamic part of the relaxation rate $R_{\mathrm{D}}^{\rho}$ due to dislocation movement a spin-locking experiment is performed on a deforming crystal $(\dot{\varepsilon} \neq 0)$ yielding $1 / T_{1 \rho}(\dot{\varepsilon})$. Subsequently, an experiment is done without deforming the crystal $(\dot{\varepsilon}=0)$. Then $R_{\mathrm{D}}^{\rho}$ is given by :

$$
R_{\mathrm{D}}^{\rho}=\left(\frac{1}{T_{1 \rho}}\right)_{\mathrm{dyn}}=\left(\frac{1}{T_{1 \rho}}\right)_{\dot{\varepsilon} \neq 0}-\left(\frac{1}{T_{1 \rho}}\right)_{\dot{\varepsilon}=0} .
$$

In figure $1 R_{\mathrm{D}}^{\rho}$ has been plotted as a function of $\dot{\varepsilon}$ 
Table I. - Compilation of the experimental results. ( $\sigma$ represents the shear stress and $a$ the shear strain.)

\begin{tabular}{|c|c|c|c|c|c|}
\hline $\begin{array}{c}\text { Compression } \\
\text { axis }\end{array}$ & $\mathbf{H}_{0}$ & $\{110\}^{\varphi}\{100\}$ & $\begin{array}{c}\sigma(\mathrm{MPa}) \\
\dot{a}=0.1 \mathrm{~s}^{-1} \\
a=6 \%\end{array}$ & $\begin{array}{c}\rho_{\mathrm{tot}} \\
10^{13} \mathrm{~m}^{-2}\end{array}$ & $L(\mu \mathrm{m})$ \\
\hline - & - & & - & - & - \\
\hline [001] & [110] & $0.5 \quad 0$ & 4.5 & 1.2 & 1.14 \\
\hline [110] & [001] & 0.25 & 10.0 & 5.7 & 0.70 \\
\hline$[10,9,13]$ & {$[7,7,-10]$} & 0.13 & 7.5 & 3.5 & 1.42 \\
\hline
\end{tabular}

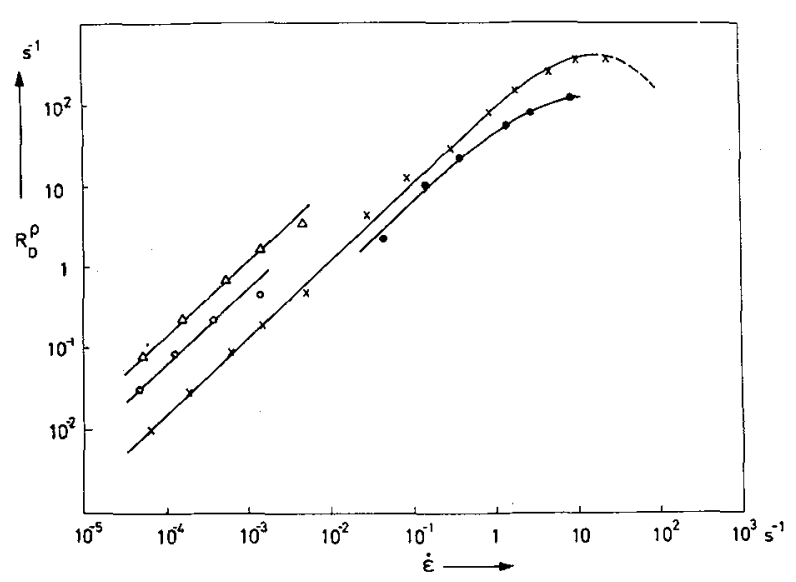

Fig. 1. - Dislocation induced part of the relaxation rate $R_{D}^{\rho}$ as a function of the strain rate $\dot{\varepsilon}$ measured on different nuclei in alkali halide single crystals, deformed in the $\langle 100\rangle$ direction $T=293 \mathrm{~K},\langle\varepsilon\rangle \simeq 3 \%, H_{0} /\langle 110\rangle . \times:{ }^{23} \mathrm{NaCl}, H_{1}=2.2 \mathrm{G}$ - $:{ }^{23} \mathrm{NaF}, H_{1}=5.5 \mathrm{G} ; \Delta:{ }^{87} \mathrm{RbCl}, H_{1}=2.0 \mathrm{G} ; \circ \mathrm{Na}{ }^{35} \mathrm{Cl}$, $H_{1}=2.2 \mathrm{G}$.

for different ultrapure alkali halide single crystals compressed in the $\langle 100\rangle$ direction. In the range $10^{-4} \mathrm{~s}^{-1} \leqslant \dot{\varepsilon} \leqslant 1 \mathrm{~s}^{-1} R_{\mathrm{D}}^{\rho}$ is found to be proportional to $\dot{\varepsilon}$ according to equation (1). From this linearity $L$ can be determined, providing the other parameters in equation (1) are known (see Table I). The term $H_{\mathrm{D}}^{2}+H_{\mathrm{Q}}^{2}$ can be obtained by measuring $\left(T_{1 \rho}\right)_{\mathrm{dyn}}$ as a function of $H_{1}^{2}[1,2]$; from lineshape analysis of the Free Induction Decay (FID) $H_{\mathrm{D}}$ and $H_{\mathrm{Q}}$ can be obtained separately. The quadrupole constant A can be calculated assuming a random distribution of dislocations on $\{110\}$ planes, for a particular ratio of the density of edge and screw dislocations : i.e. $4: 1[5,6]$.

Assuming that the mean distance $L$ has approximately the same value for all the alkali halide crystals investigated as shown in figure 1 , one can calculate the ratio of the relaxation rates using equation (1). The computational results are listed in table II, together with the experimentally determined values obtained from those depicted in figure 1 . The agreement between those results demonstrates clearly the presence of a uniform $L$ for the different types of crystals. It confirms that other dislocations are the main strong obstacles for dislocation movement in pure alkali halide single crystals [7].
Table II. - The ratio between the relaxation rates $R_{\mathrm{D}}^{\rho}$ measured in different alkali halide single crystals.

$\begin{array}{lcc} & \text { Experiment } & \text { Theory } \\ & - & - \\ { }^{23} \mathrm{NaF} /{ }^{23} \mathrm{NaCl} & 0.52 & 0.46 \\ { }^{87} \mathrm{RbCl} /{ }^{2} \mathrm{NaCl} & 7.8 & 8.0 \\ \mathrm{Na}^{35} \mathrm{Cl} /{ }^{23} \mathrm{NaCl} & 4.4 & 4.7\end{array}$

From the maximum value found in the relaxation rate for $\mathrm{NaCl}$ at $\dot{\varepsilon}=20 \mathrm{~s}^{-1}$ the mean waiting time at obstacles can be determined directly because

$$
2 \omega_{\text {eff }} \tau \equiv 2 \gamma\left(H_{1}^{2}+H_{\mathbf{D}}^{2}+H_{\mathrm{Q}}^{2}\right)^{1 / 2} \cdot \tau=1[4] .
$$

It follows that $\tau=28 \mu \mathrm{s}$. With the value of $L$ as mentioned above we find at $\dot{\varepsilon}=20 \mathrm{~s}^{-1}$ :

$$
\langle v\rangle=40 \times 10^{-3} \mathrm{~ms}^{-1} \text {. }
$$

From $\left(R_{\mathrm{D}}^{\rho}\right)_{\max }$ also the mobile fraction of dislocations is obtained : $\rho_{\mathrm{m}} / \rho_{\mathrm{i}}=0.2$.

These results have been compared with those obtained from $\mathrm{NaCl}$ single crystals compressed along [110] and a direction $9^{\circ}$ off [111], i.e. [10,9, 13], see figure 2
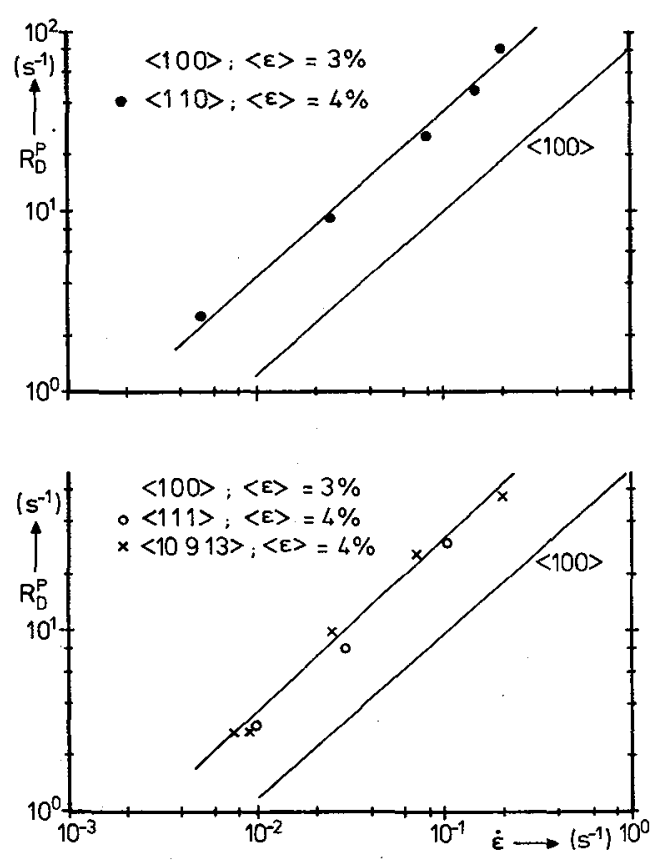

Fig. 2. - Dislocation induced part of the relaxation rate $R_{\mathrm{D}}^{\rho}$ as a function of the strain rate $\dot{\varepsilon}$ measured on ${ }^{23} \mathrm{NaCl}$ single crystals deformed in the $\langle 100\rangle,\langle 110\rangle,\langle 111\rangle$ and $\langle 10,9,13\rangle$ directions. $T=295 \mathrm{~K}, H_{1}=2.2 \mathrm{G}$. 
and table I. The total dislocation density for [001] crystals has been determined by line shape analysis, whereas for the other compression directions a value has been estimated using the proportionality between $\sigma$ and $\sqrt{\rho}[8,9]$.

3. Discussion and conclusions. - The results show that for [110] crystals the mean free path for dislocations is shorter than for [001] crystals. This confirms suggestions made by Haasen and Hesse $[6,10]$, that in [110] crystals dislocations on $\{100\}$ planes can interfere with dislocations on the primary $\{110\}$ slip planes, thus shortening the mean free path (for [110] compression the Schmid factor for slip on (100) and (010) is 0.35 whereas it is zero for [001] compression). Crystals which deviated only $1^{\circ}$ from $[10,9,13]$ have been investigated by Klyavin et al. $[11$, 12]. They found that in $\mathrm{NaCl}$ single crystals slipsystems $\{001\}\langle 011\rangle$ are occurring usually as much as slip in the $\{110\}\langle 1 \overline{1} 0\rangle$ systems. It is a consequence of the fact that the Schmid factor for the former is at a maximum of 0.5 and for the latter 0.13 . To some extent, independent slip on both systems could therefore plausibly account for the fact that

$$
L([10,9,13])>L([001]) .
$$

According to a paper by Strunk et al. [13] also, slip on $\{111\}$ for [111] oriented crystals was found to be important. Some very recent $R_{\mathrm{D}}^{\rho}$ experiments on [111] $\mathrm{NaCl}$ single crystals exhibit qualitatively the same results as on $[10,9,13]$ crystals. However, detailed analyses have to be carried out in order to come to more conclusive remarks on [111] crystals, which will be published elsewhere.

Finally, in figure 3 measurements of the mean free path $L$ as a function of temperature are presented. The cation-vacancy diffusion process causes the increment of $L$ for $T \gtrsim 410 \mathrm{~K}$ since climb of dislocations plays a major role in the deformation behaviour of $\mathrm{NaCl}$ crystals in the temperature range above $425 \mathrm{~K}$ [14]. Due to the process of diffusion-controlled

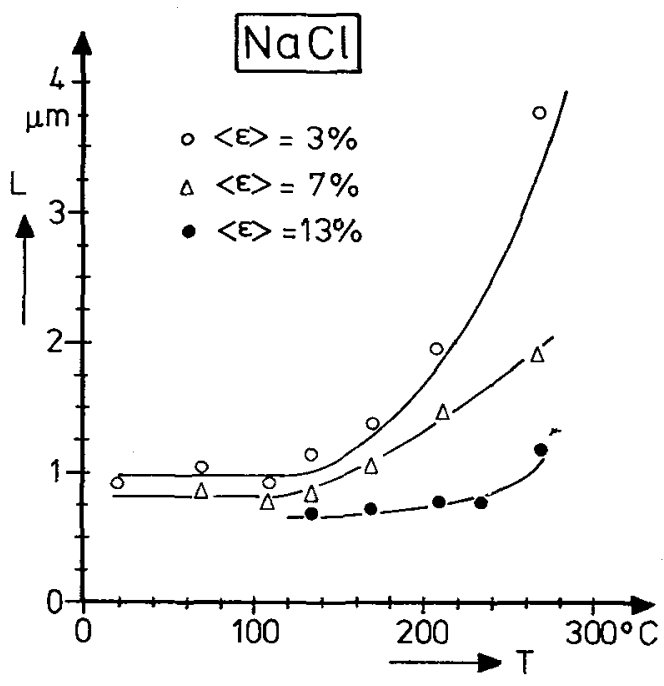

Fig. 3. - Mean free path $L$ as a function of temperature for $\mathrm{NaCl}<001>$ crystals. $\dot{\varepsilon}=0.5 \mathrm{~s}^{-1}$.

climbing the mobile dislocations are able to overcome weak obstacles, that leads to an increase of the mean distance $L$ of the acting obstacles. When increasing the concentration of the strong obstacles by means of plastic deformation, the increment of $L$ will start at a higher temperature using higher plastic strain (see Fig. 3). The extent to which $L$ increases is obviously smaller in the case of highly deformed crystals which is based on the change of the ratio strong/weak obstacles.

Acknowledgments. - Particular thanks are due to Dr. J. Th. M. de Hosson for reading and making critical comments on the manuscript. The work is part of the research program of the Foundation for the Fundamental Research on Matter (FOM) and has been made possible by financial support from the Netherlands Organization for the Advancement of Pure Research (ZWO), (The Hague) and the Deutsche Forschungsgemeinschaft (Germany).

\section{DISCUSSION}

\section{Question. - J. CASTAING.}

How can you be sure that you see dislocation motion and not vacancy e.g. induced by jog-dragging motion?

$$
\text { Reply. - O. KANERT. }
$$

The density of point defects (vacancies) increases with increasing strain. If the relaxation rate would be influenced by these defects, one would expect it to be a function of $\varepsilon$. This is not observed. Theoretically, the long-range stress fields of mobile dislocations induce a larger quadrupole relaxation rate than the short-range stress fields of mobile vacancies. Furthermore, at low temperatures $(T<300 \mathrm{~K})$ the vacancies do not move i.e. there is no relaxation effect.

\section{Question. - L. W. HoBBs.}

Are your Stage I measurements well before the Stage I/Stage II transition where the dislocation density on secondary (orthogonal oblique) systems increases dramatically?

\section{Reply. - A. W. SLEeswyK.}

We have measured, as others did, the total dislocation density as a function of applied stress $\sigma$ and found that proportionality of $\rho_{t}^{1 / 2}$ with $\sigma$ is not changed going from stage I to stage II. On the other hand, the direct measurement of mobile dislocation density ended well in stage II, and represented therefore an integration over stage I and II. 


\section{References}

[1] HuT, G., SleesWyK, A. W., Hackelöer, H. J., Selbach, H., KANerT, O., Phys. Rev. B 14 (1976) 921.

[2] Hackelöer, H. J., Selbach, H., Kanert, O., Sleeswyk, A. W., Hut, G., Phys. Status Solidi (b) 80 (1977) 235.

[3] Alsem, W. H. M., Faraday Symp. of the Chem. Soc. 13, Pulsed Nuclear Magnetic Resonance in Solids (1978) in press.

[4] Wolf; D., Kanert, O., Phys. Rev. B 16 (1977) 4776

[5] Davidge, R. W., Pratt, P. L., Phys. Status Solidi 6 (1964) 759.

[6] Hesse, J., Phys. Status Solidi 9 (1965) 209.

[7] Frank, W., Phys. Status Solidi 26 (1968) 197.
[8] Matucha, K. H., Franzbecker, W., Wilkens, M., Phys. Status Solidi 33 (1969) 493.

[9] Hesse, J., Hobes, L. W., Phys. Status Solidi 14 (1972) 599.

[10] Haasen, P., Hesse, J., Disc. Faraday Soc. 38 (1964) 38.

[11] Kryavin, O. V., Simashko, S. G., Stepanov, A. V., Sov. Phys.-Sol. State 15 (1973) 274.

[12] Klyavin, O. V., Simashko, S. G., Sov. Phys.-Sol. State 16 (1974) 898.

[13] Bhagavan Raju, I. V. K., Strunk, H., Phys. Status Solidi (a) 53 (1979) 211.

[14] Evans, A. G., Rawlings, R. D., Phys. Status Solidi 34 (1969) 9. 